\title{
Com-1/p8 acts as a putative tumour suppressor in prostate cancer
}

\author{
WEN G. JIANG ${ }^{1}$, GAYNOR DAVIES ${ }^{1}$, TRACEY A. MARTIN ${ }^{1}$, \\ HOWARD KYNASTON ${ }^{1}$, MALCOLM D. MASON ${ }^{2}$ and OYSTEIN FODSTAD ${ }^{3,4}$
}

\begin{abstract}
${ }^{1}$ Metastasis and Angiogenesis Research Group, ${ }^{2}$ Clinical Oncology, Cardiff University School of Medicine, Cardiff, UK; ${ }^{3}$ Cancer Research Institute, University of South Alabama, Mobile, AL, USA; ${ }^{4}$ Institute for Cancer Research, Rikshospitalet-Radiumhospitalet Medical Center, and Faculty of Medicine, University of Oslo, Oslo, Norway
\end{abstract}

Received May 9, 2006; Accepted June 29, 2006

\begin{abstract}
Com-1, candidate of metastasis-1, also known as $\mathrm{p} 8$, is a recently discovered molecule with a putative role in determining the metastatic nature of cancer cells. We have investigated the expression of Com-1 in normal and malignant human prostate tissues and its molecular interaction within prostate cancer cells. The expression of Com-1 in human prostate tissues and prostate cancer cell lines was assessed at both the mRNA and protein levels, by RT-PCR and immunohistochemistry. The staining intensity of Com-1 was semiquantified using computer assisted image analysis. Fulllength Com-1 cDNA was isolated from normal mammary tissues. Ribozyme transgenes that specifically target human Com- 1 were constructed using the pEF6/V5-His vector. The growth of prostate cancer cells in vitro and tumour growth in vivo (athymic mice model) following Com-1 overexpression in prostate cancer cells were determined. In normal prostate tissues, the epithelial cells strongly stained Com-1, both in the cytoplasm and in the nucleus. In contrast, prostate cancer cells in tumour tissue showed substantially reduced Com-1 staining levels $(\mathrm{p}<0.05$ compared to normal cells for both cytoplasmic and nucleus staining), whereas the prostate cancer cell lines PC-3, DU145 and CA-HPV10 widely expressed Com-1. Transfection of these cells with hammerhead ribozyme transgenes resulted in the loss of expression of the Com-1 transcript. Using an in vitro invasion assay we found that the loss of Com-1 from prostate cancer cells increased their invasiveness. Knockout of Com-1 also resulted in the accelerated growth of all three cell lines. Forced overexpression of Com-1/ p8 in prostate cancer cells was able to reverse the changes in invasiveness and growth seen with the Com-1 knock-out cells. In a spontaneous tumour model, it
\end{abstract}

Correspondence to: Dr Wen G. Jiang, Metastasis and Angiogenesis Research Group, Cardiff University School of Medicine, Heath Park, Cardiff CF14 4XN, UK

E-mail: jiangw@cf.ac.uk

Key words: Com-1, p8, prostate cancer, invasion, prostate cancer model was demonstrated that PC-3 cells with forced overexpression of Com-1 (PC-3 $\left.3^{\text {comlexp }}\right)$ had a significantly slower rate of growth compared with control cells (tumour size $36.6 \pm 31.2 \mathrm{vs}$ $114.3 \pm 68.1 \mathrm{~mm}^{3}$, for tumours from PC-3 $3^{\text {comlexp }}$ and control PC- 3 cells, respectively, $\mathrm{p}=0.0023)$. In conclusion, Com- $1 / \mathrm{p} 8$ was expressed at lower levels in human prostate cancer cells compared with normal epithelial cells. Com-1/p8 levels are inversely correlated with the invasiveness and growth of prostate cancer cells in vitro and the overexpression of Com-1 reduced the growth of prostate tumours in vivo. Com- $1 / \mathrm{p} 8$ is a potential tumour suppressor in human prostate cancer.

\section{Introduction}

The Com-1, candidate of metastasis-1, gene was discovered by differential display of cDNA from breast cancer metastases to the brain of nude rats, and was thought to be a candidate molecule that assists the metastatic process of cancer cells (1). The protein was subsequently found to be identical to a protein known as $\mathrm{p} 8$, identified from the $\mathrm{t}(\mathrm{X} ; 14)(\mathrm{q} 28 ; \mathrm{q} 11.2)$ translocation, which is located on chromosome Xq28 and was overexpressed in leukemic cells (2). The molecule was initially thought to play a role in promoting metastasis and have some degree of mitogenic activity $(1,3)$. Moreover, when transformed with a retroviral vector encoding Com-1/p8, mouse embryo fibroblasts became tumourigenic in a murine model (4). Interestingly, cytoplasmic staining of Com-1 is frequently seen in poorly differentiated tumour cells, compared with well and moderately differentiated tumours and normal cells, which frequently display a nucleus staining pattern. Com- 1 staining was more intense in thyroid cancer than in the normal thyroid tissue (5). Su et al $(6,7)$ reported overexpression of Com-1/p8 in clinical pancreatic cancer and an inverse correlation between Com-1/p8 and apoptosis in pancreatic cancer cells. In pancreatic islet and $B$ cells, nuclear $\mathrm{p} 8$ was associated with glucose-independent cell growth (8), and in acute pancreatitis, Com-1/p8 enhanced the expression of PAP-1 (pancreatitisassociated protein-1) (9).

Subsequent studies have, however, indicated that rather than acting as a factor that stimulates tumour aggressiveness, Com-1 may act as an inhibitory molecule in cancer cells. Thus, Com-1 is associated with 1,25-Dihydroxyvitamin D3- 
induced growth inhibition of breast cancer cells, in that 1,25Dihydroxyvitamin D3 induced a rapid and substantial rise of Com-1 with a simultaneous reduction in growth rate (10). Recently, it was further demonstrated that the transfection of pancreatic cancer cells with Com-1/p8 resulted in growth inhibition (11), and that p8-silenced cells by way of an antisense approach grew more rapidly than control cells transfected with the empty retrovirus. It was also shown that inhibitors to MEK1/2 and JNK can upregulate p8 expression, and that in fibroblasts $\mathrm{p} 8$ is a cell growth inhibitor that facilitates apoptosis induced by DNA damage (12) which may involve p53.

The p8 polypeptide is a phosphoprotein subject to constitutive degradation by the ubiquitin/proteasome system mediated by phosphatidylinositol 3-kinase and protein kinase $\mathrm{B} / \mathrm{Akt}$. By contrast, stabilization of the $\mathrm{p} 8$ protein requires glycogen synthase kinase-3 (13). Garcia-Montero et al (14) have shown that TGF- $\beta-1$ can activate Com- $1 / \mathrm{p} 8$ expression, which in turn enhances the Smad-transactivation in the TGF- $B$ pathway. Com-1/p8 is primarily a nuclear protein and has been suggested to possibly be involved in the p27kip 1 and p21cip1 pathway. We have recently shown that Com-1 expression in human breast cancer is reduced and that the reduction of the Com-1 transcript is associated with the aggressiveness of breast tumours (15). Furthermore, we recently reported that Com-1 interacts with ER- $\beta$ and counteracts oestrogen-mediated effects on breast cancer cells (16).

No studies on human prostate cancer or prostate cancer cells have until now been reported. In the present study we first examined the protein levels of Com-1/p8 in human prostate tissues and prostate cancer cells, and subsequently we explored the role of Com-1 in the growth and invasion of prostate cancer cells, in vitro and in vivo, and report that Com-1/p8 plays a potential tumour suppressor role in prostate cancer.

\section{Materials and methods}

Materials. RNA extraction and RT kits were obtained from AbGene Ltd, Surrey, UK. PCR primers were designed using a Beacon designer (Palo Alto, CA) and synthesised by Invitrogen Ltd (Pasley, UK). Molecular biology grade agarose and DNA ladder were obtained from Invitrogen, and the master mix for routine PCR and quantitative PCR from
AbGene. Rabbit anti-human Com-1 (p8) polyclonal antibodies were purchased from Santa Cruz Biotechnologies (Santa Cruz, CA) and a biotin universal staining kit was from Vector Laboratories (Nottingham, UK).

Samples and cell lines. Human prostate cancer cell lines PC-3, DU-145, CA-HPV-10 and LN-Cap were obtained from ATCC (American Type Cell Culture, Rockville, MD). Paraffin embedded prostate tissues were obtained from the Department of Pathology, Wales College of Medicine after approval by the local ethics committee.

Immunohistochemical staining of Com-1. Paraffin sections of prostate tissues were first dewaxed using a series of zylene and ethanol washes. Rehydrated sections were subject to antigen retrieval using the microwave method as previously reported (17). The sections were then placed in 'Optimax' wash buffer for 5-10 min to rehydrate and incubated for $20 \mathrm{~min}$ in a $0.6 \%$ BSA blocking solution and probed with the primary antibody. Following extensive washing, sections were incubated for $30 \mathrm{~min}$ with the secondary biotinylated antibody (Multilink swine anti-goat/mouse/rabbit immunoglobulin, Dako Inc. Carpinteria, CA). Following washing, an avidin-biotin complex (Vector Laboratories) was applied to the sections followed by extensive washing. Diamino benzidine chromogen (Vector Laboratoriess) was then added to the sections, which were incubated in the dark for $5 \mathrm{~min}$. Sections were then counter stained in Gill's haematoxylin and dehydrated in ascending grades of methanol before clearing in xylene and mounting under a cover slip.

RNA extraction and cDNA synthesis. RNA was extracted from cells and the concentration of RNA was determined using a UV spectrophotometer. Reverse transcription was performed using an RT kit with an anchored oligo-dt primer (AbGene), using $1 \mu \mathrm{g}$ of total RNA in 96-well plates. The quality of the cDNA was verified using $\beta$-actin primers.

Construction of hammerhead ribozyme transgenes targeting human Com-1/p8, and human Com-1 expression cassette. This was conducted as we recently reported $(16,18)$. Hammerhead ribozymes that specifically target a GTC and a UUC site of human Com-1 (GenBank accession af135266, position 189 and 68, respectively), based on the secondary structure of Com-1 using Zuker's mfold programme were

Table I. PCR primer sequences.

Sense (5'-'3)

Antisense (5'-'3)

Com-1 quantitation and screening

Com-1 Expression

Com-1 ribozyme- 8

Com-1 ribozyme- 9

Ribozyme screening

B-actin cetggatgaatctgacctc

atggccaccttccac

ctgcagcttctctcttggtgcctgatgagtccgtgagga

ctgcagctggttgctggtggctgatgagtccgtgagga

ctgatgagtccgtgaggacgaa

gctgatttgatggagttgga actgaacctgaccgtacacaagcagcttctctcttggtg actgcgecgtgccectcg

actagtggaggccggaaaggtttcgtcctcacggact actagtatggccacctttttcgtcctcacggact

ttcgtcctcacggactcatcag

tcagctacttgttcttgagtgaa 


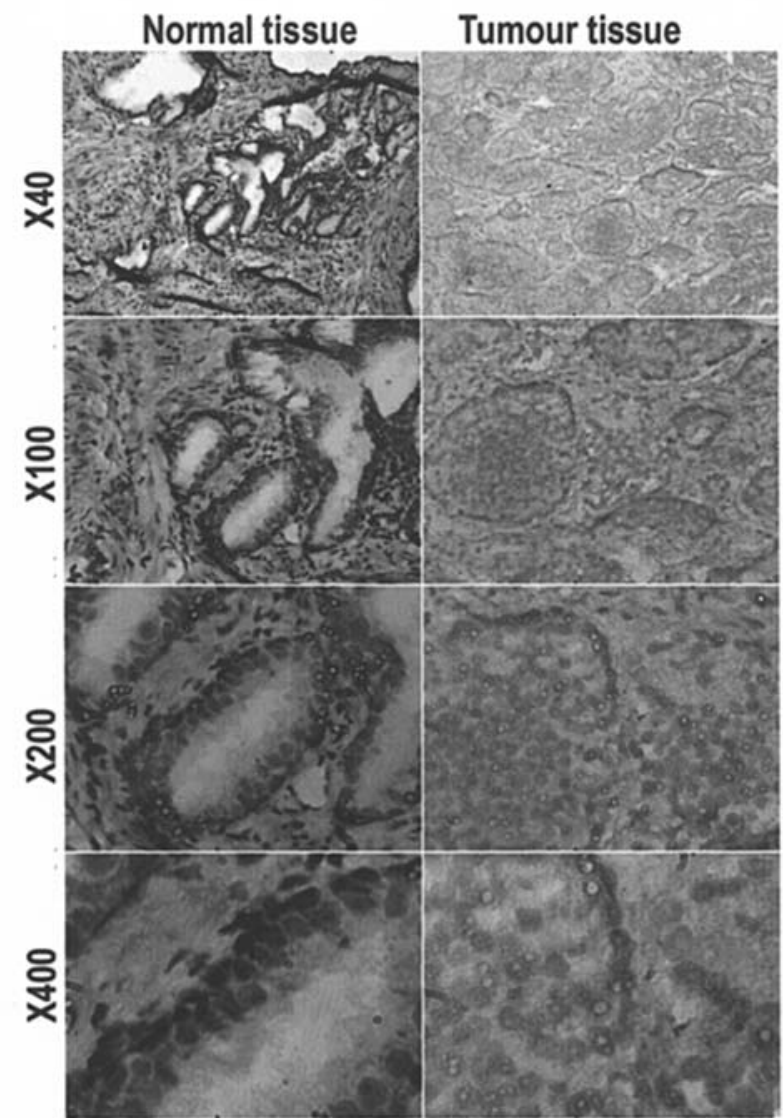

Figure 1. Com-1 staining in prostate tissues. Left panel, normal prostate tissue; right, low-grade prostate cancer tissue. Com-1 was stained in normal prostate epithelial cells. Staining in prostate cancer cells was greatly reduced.

constructed. Iouch-down PCK was used to generate the ribozymes with the primers listed in Table I. These were subsequently cloned into a pEF6/V5-His vector, using ampicillin and blasticidin as selection markers for prokaryotic and mammalian cells, respectively, and then amplified in E. coli, purified, verified and used for electroporation of prostate cancer cells. Full-length human Com-1 cDNA was generated from normal mammary tissue using primers, Com1ExF and Com1ExR (Table I). The sequence verified product was then TA cloned into pEF6/V5His and prepared in a similar manner to the ribozyme transgenes and used for transfection. The above procedure generated the following stably transfected cells from PC-3, DU145 and CA-HPV-10: Com-1 knockout cells, PC3 ${ }^{\text {scom1, }}$ DU145 ${ }^{\Delta \mathrm{com} 1}$, CA-HPV ${ }^{\Delta \mathrm{com} 1}$; Com-1 overexpressing cells, PC-3 $3^{\text {comlExp }}$ DU145 ${ }^{\text {comlExp }}$, CA-HPV ${ }^{\text {com1Exp; }}$ and plasmid only control cells, PC3 ${ }^{\mathrm{pEFa}}$, DU145 ${ }^{\mathrm{pEFa}}$, CA-HPV ${ }^{\mathrm{pEFa}}$, used together with the respective wild-types.

In vitro invasion analysis and cell growth assay. This was performed as previously reported and modified in our laboratory (19). Briefly, transwell inserts (upper chamber) with an $8-\mu \mathrm{m}$ pore size were coated with $50 \mu \mathrm{g} /$ insert of Matrigel and air-dried, before being rehydrated. Then, $2 \times 10^{4}$ cells were added to each well, with or without $\mathrm{HGF} / \mathrm{SF}$. After $72 \mathrm{~h}$, cells that had migrated through the matrix and adhered to the other side of the insert were fixed and stained with $0.5 \%(\mathrm{w} / \mathrm{v})$ crystal violet. The invaded cells stained with crystal violet were extracted with $10 \%$ (v/v) acetic acid and the absorbance was obtained using a multiplate reader. For cell growth assay, control cells and stably transfected cells were plated into a 96-well plate at 2,500 cells/well. The cells were fixed in $10 \%$ formaldehyde at the day of plating and daily for 6 subsequent days, and then stained with $0.5 \%$ (w/v) crystal violet. Following washing, the stained crystal was extracted with $10 \%$ (v/v) acetic acid and the absorbance determined using a multiplate reader. The growth of cells is represented here as absorbance (mean $\pm \mathrm{SD}$ ).

Effects of overexpressing Com-1 on the growth of prostate tumour in vivo. This was based on a model as recently described (20). Briefly, athymic female nude mice of 4-6 weeks old were purchased from B\&K (Aldbrough, Yorkshire, Endland, UK) and maintained in filter-topped units. The cell suspension $(100 \mu \mathrm{l})$ (with $1 \times 10^{6}$ cells in $2.0 \mathrm{mg} / \mathrm{ml}$ Matrigel) was injected subcutaneously. PC- $3^{\text {com1Exp }}$ and PC $3^{\mathrm{pEFa}}$ were used. The Mice were weighed and the tumour sizes measured twice weekly for 4 weeks. Mice with a weight loss $>25 \%$ and tumour size $>1 \mathrm{~cm}$ in any dimension were terminated according to the UK Home Office and UKCCCR guideline. The volume of the tumour was determined using the formula: tumour volume $=0.523 \mathrm{x}$ width $^{2} \mathrm{x}$ length (19). At the conclusion of
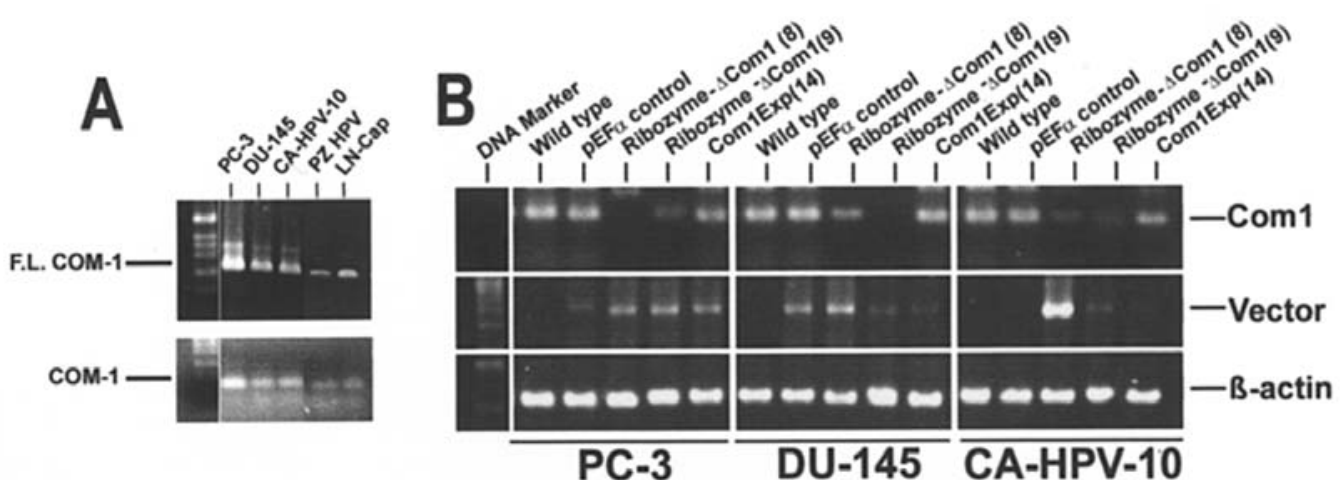

Figure 2. Expression of Com-1 in prostate cancer cells (A) and genetic manipulation (B). All five prostate cancer cell lines expressed Com-1 mRNA. (F.L.Com-1, full-length Com-1; bottom panel in A, amplified internal region of Com-1). Two ribozyme transgenes had knockdown expression of Com-1 mRNA from all three prostate cancer cells (B). 

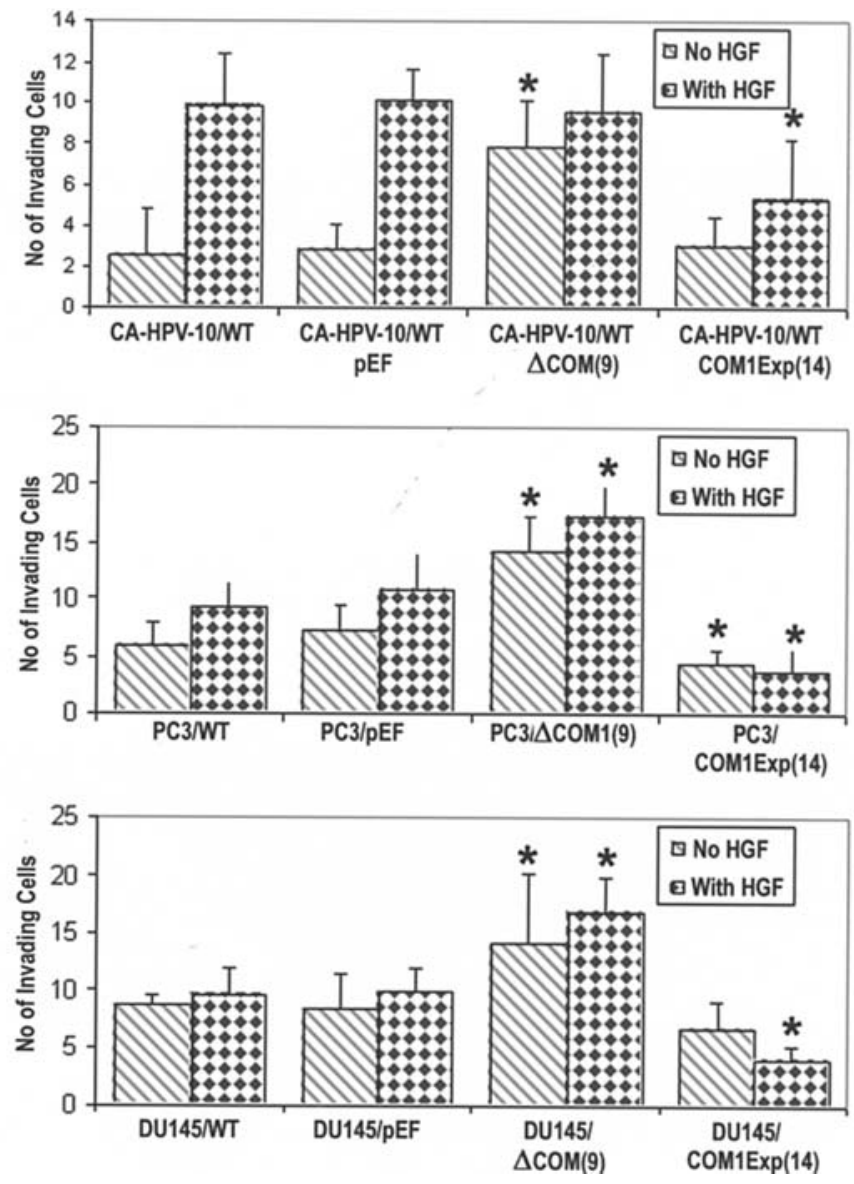

Figure 3. Effects of Com-1 expression on the invasiveness, in vitro. Top, CA-HPV prostate cancer cells; middle, PC-3 cells; bottom, DU145 prostate cancer cells. ${ }^{*} \mathrm{p}<0.05$ vs the respective controls.

the experiment, animals were terminally anaesthetised, primary tumours were dissected, weighed and frozen at $-80^{\circ} \mathrm{C}$. A portion of the primary tumours was fixed for histological examination.

\section{Results}

Reduced Com-1 staining in prostate cancer tissue. In order to estimate the protein levels of Com-1 in human prostate tissues, we conducted immunohistochemical analysis using archival normal and malignant prostate tissues. As revealed in Fig. 1, normal prostate epithelial cells had a stronger staining of Com-1 both in the nucleus and in the cytoplasm. In contrast, normal epithelial cells had a strong cytoplasmic staining. In tumour tissues, however, the malignant cells showed a substantially reduced staining of Com-1, in the nucleus as well as in the cytoplasmic region.

Com-1 is associated with the growth rate and invasiveness of prostate cancer cells. To test the potential role of Com-1 in prostate cancer cells, we created the following cell variants from the established cell lines: Com-1-knockdown cells using the ribozyme transgene specific to human Com-1, and Com-1 overexpressing cells using a full-length coding region of Com-1 isolated from normal human tissues. As shown in Fig. 2 , despite all the wild-type prostate cancer cell lines being positive for Com-1, Com-1 ribozyme transgenes successfully reduced (ribozyme 8) or eliminated (ribozyme 9) the expression of the Com-1 transcript from the prostate cancer cells. We also engineered prostate cancer cells that overexpressed Com-1 (Com1Exp) (Fig. 2).

Using these genetically modified cells, in vitro invasion analysis was conducted. The knockout of Com-1 prostate cancer cells had enabled the cells to become more invasive (Fig. 3 for three respective cells). Interestingly, forced expression of Com-1 using a mammalian expression system in these cells made the cells less invasive compared with the control and wild-type cells.

Using the same cells, we further tested the rate of cell growth over a 7-day period. Cells that had lost Com-1 by way of ribozyme transgenes displayed a faster rate of growth, compared with cells transfected with control vectors and with wild-type cells (Fig. 3, left panel, 3 days; right panel, 7 days). Furthermore, cells with forced overexpression of Com-1 displayed a slower growth rate, particularly in PC-3 cells.

Forced overexpression of Com-1/p8 in prostate cancer cells resulted in slower tumour growth in vivo. We went on to examine if manipulating the level of expression of Com-1 in prostate cancer cells impacted the tumour growth in vivo, by using an athymic mouse model. In the current study, we tested PC-3 cells with forced overexpression of Com-1 (PC-3 ${ }^{\text {comlExp }}$ cells), cells with significantly reduced invasiveness, in vitro

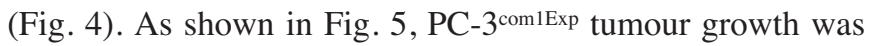
at a significantly slower pace than the control cells $\left({ }^{*} \mathrm{p}<0.01\right.$ vs control tumours) and the difference occurred at an early stage.

\section{Discussion}

The current study has examined the staining pattern of Com-1/ p8 in human prostate tissues and tested the impact of genetically manipulating the expression of Com- 1 in prostate cancer cells on the growth and invasion of prostate cancer cells.

Similar to human breast cancer and thyroid cancer, Com-1 presents at low levels in prostate tumour cells, compared with normal prostate epithelial cells. This is in contrast to that observed with pancreatic cancer cells, in that cancer cells had higher staining than normal cells. This would indicate that in solid human tumours, Com-1 exists at lower levels, although the opposite may also operate. It is interesting to note that two potential phenomena exist in solid tumours: substantial loss of Com-1 protein from cancer cells and a potential shift from (loss of) the nucleus to the cytoplasm. The first case was seen here in prostate cancer, the latter case was reported in thyroid cancer and breast cancer. The nucleus nature of Com-1 is particularly interesting, as it further indicates the possibility of a nuclear connection in the function of Com-1. Thus, changes in the overall level of staining of Com-1 in prostate cancer cells and in cellular location appear to be a feature in human prostate tumour tissues.

In the present study, we employed methods to genetically alter the expression of Com-1 in prostate cancer cells, namely the ribozyme approach and overexpression approach, respectively. The loss of Com-1 by way of hammerhead 

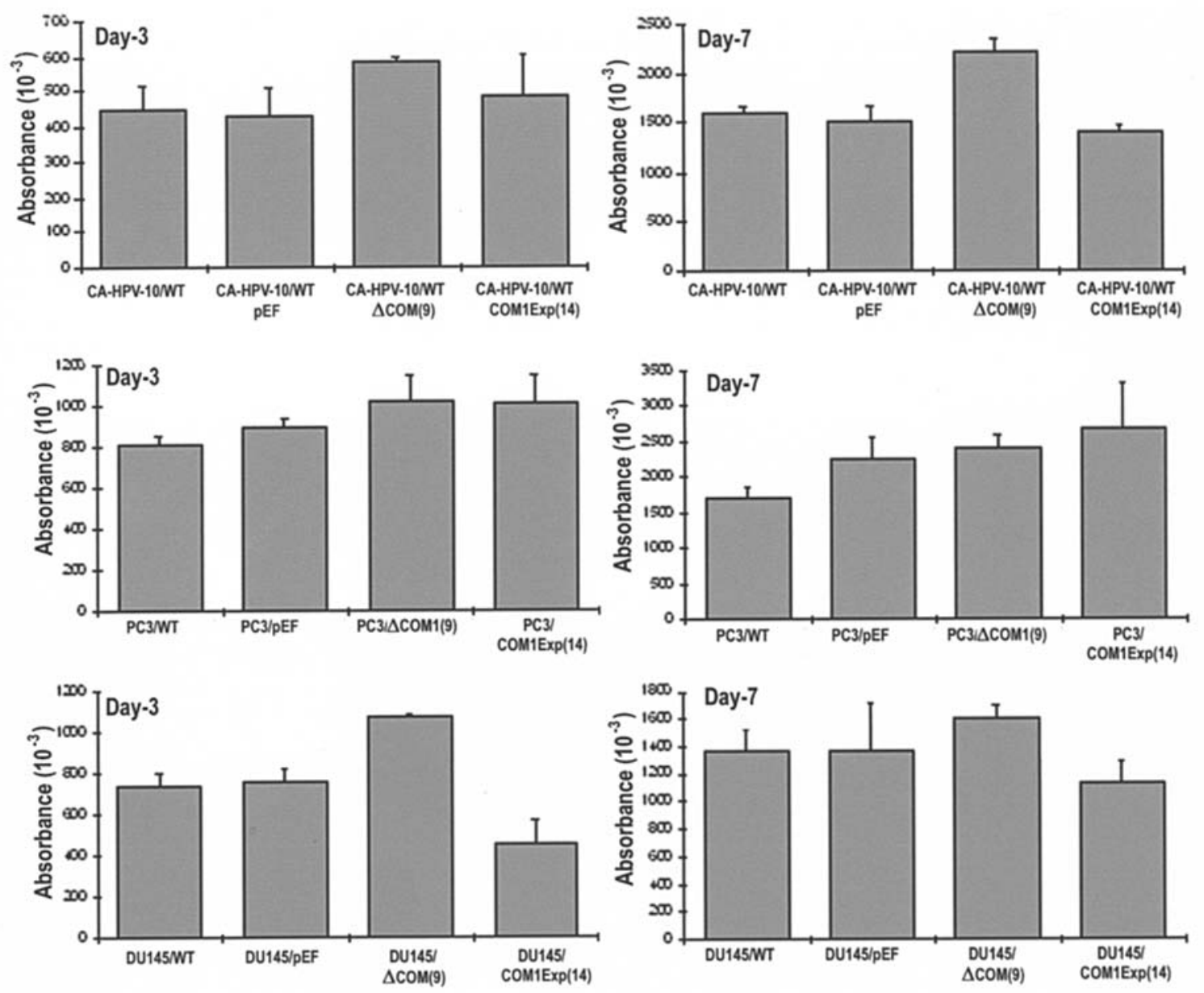

Figure 4. Expression of Com-1 and the in vitro growth of prostate cancer cells. Top, CA-HPV prostate cancer cells; middle, PC-3 cells; bottom, DU145 prostate cancer cells. Left panel, 3 days; right panel, 7 days) of prostate cancer cells. Knockdown expression of Com-1 from prostate cancer cells resulted in an increase in the rate of growth in vitro.

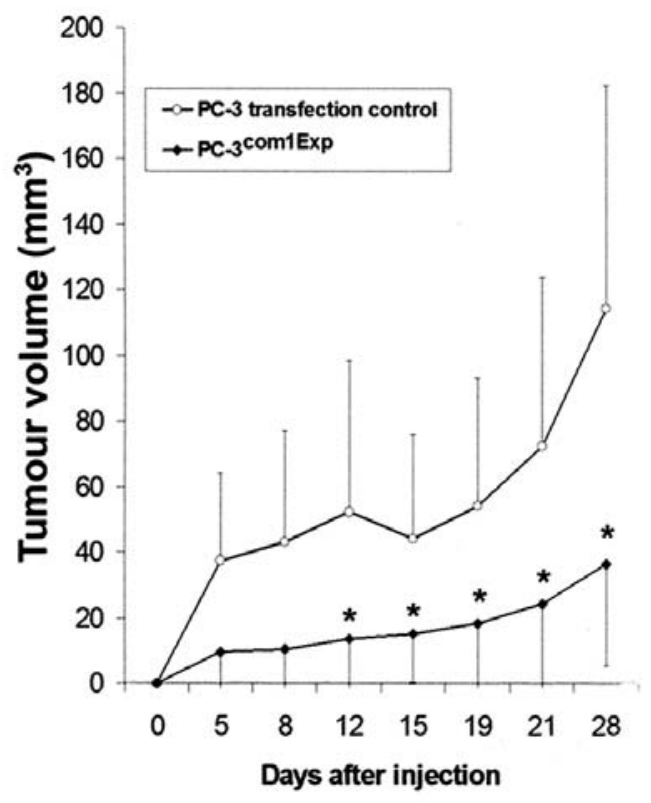

Figure 5. Effects of Com-1 overexpression on the growth of prostate tumours in vivo. Com-1 expressing PC-3 cells and control transfected PC-3 cells were subcutaneously injected into athymic nude mice. Tumour growth was monitored over a 4 -week period. There was a significantly slower growth with PC-3 $3^{\text {com1Exp }}$ cells, compared with control cells. ${ }^{*} \mathrm{p}<0.01$ vs the control of the respective time point. ribozyme transgenes resulted in more invasiveness compared with control cells. In clear contrast, forced overexpression of Com-1 in all three prostate cancer cell lines resulted in lower in vitro invasion. This indicates that Com- 1 may play a key role in the control of the aggressiveness of prostate cancer, via mechanism(s) yet to be identified. The current study has also demonstrated that loss of Com-1 also resulted in an accelerated cell growth in vitro. This growth regulatory role of Com-1 has been tentatively indicated in other tumour cells including breast cancer cells and thyroid cancer cells, in which Vit D3 inhibition of cell growth was associated with a rise of Com-1. In pancreatic cancer cells and in fibroblasts, overexpression of Com-1 is associated with inhibitory effects on cell growth and/or with accelerated apoptosis. This together with the effects observed in human solid tumours (breast, prostate and thyroid) $(5,6,7,15)$ strongly suggest that Com-1 is a potential tumour suppressor in these solid tumours. This suggestion is further supported by our in vivo results, in which prostate cancer cells that overexpress Com1 grew signicantly more slowly.

Presently, it is not entirely clear by which mechanism(s) Com-1 regulates the growth of prostate cancer. In the present study, female nude mice were used in in vivo analysis which, to some degree, suggests that male hormones perhaps play a small role here. However, we have tantalising evidence to 
suggest that a nuclear receptor complex, PPAR- $\gamma$, may have a role to play in this regulation. This is currently under investigation. Recently, it has been shown that Com-1/p8 is one of the key modulators in the antitumour (pro-apoptotic) effects of the cannabinoids and $\mathrm{p} 8$ mediates its apoptotic effect via upregulation of the endoplasmic reticulum stressrelated genes ATF-4, CHOP, and TRB3 (21). Finally, it has been recently demonstrated that interaction between Com-1/p8 and prothymosin $\alpha(\operatorname{ProT} \alpha)$ is a key mechanism in staurosporine-induced apoptotic response in HeLa cells (22). The role of these pathways in prostate cancer require further investigation.

In conclusion, the current study has shown that prostate cancer cells have low protein levels of Com-1 compared with normal epithelial cells. The knockout of Com-2 expression from prostate cancer cells rendered them more aggressive and Com-1 overexpressed prostate cancer cells grow smaller tumours in vivo. These results point to Com-1/p8 as a potential tumour suppressor in human prostate cancer.

\section{Acknowledgements}

The authors thank Cancer Research Wales for supporting this work.

\section{References}

1. Ree AH, Tvermyr M, Engebraaten O, Rooman M, Rosok O, Hovig E, Meza-Zepeda LA, Bruland OS and Fodstad O: Expression of a novel factor in human breast cancer cells with metastatic potential. Cancer Res 59: 4675-4680, 1999.

2. Soulier J, Madani A, Cacheux V, Rosenzwajg M, Sigaux F and Stern MH: The MTCP-1/c6.1B gene encodes for a cytoplasmic $8 \mathrm{kD}$ protein overexpressed in T cell leukemia bearing a $\mathrm{t}(\mathrm{X} ; 14)$ translocation. Oncogene 9: 3565-3570, 1994

3. Vasseur S, Vidal Mallo G, Fiedler F, Bodeker H, Canepa E, Moreno S and Iovanna JL: Cloning and expression of the human $\mathrm{p} 8$, a nuclear protein with mitogenic activity. Eur J Biochem 259: 670-675, 1999.

4. Vasseur S, Hoffmeister A, Garcia-Montero A, Mallo GV, Feil R, Kuhbandner S, Dagorn JC and Iovanna JL: P8-deficient fibroblasts grow more rapidly and are more resistant to adriamycininduced apoptosis. Oncogene 21: 1685-1694, 2002.

5. Ito Y, Yoshida H, Motoo Y, Miyoshi E, Iovanna JL, Tomoda C, Uruno T, Takamura Y, Miya A, Kobayashi K, Matsuzuka F, Matsuura N, Kuma K and Miyauchi A: Expression and cellular localization of p8 protein in thyroid neoplasms. Cancer Lett 201: 237-244, 2003

6. Su SB, Motoo Y, Iovanna JL, Berthezene P, Xie MJ, Mouri H, Ohtsubo K, Matsubara F and Sawabu N: Overexpression of p8 is inversely correlated with apoptosis in pancreatic cancer. Clin Cancer Res 7: 1320-1324, 2001

7. Su SB, Motoo Y, Iovanna JL, Xie MJ, Mouri H, Ohtsubo K, Yamaguchi Y, Watanabe H, Okai T, Matsubara F and Sawabu N: Expression of $\mathrm{p} 8$ in human pancreatic cancer. Clin Cancer Res 7: 309-313. 2001.
8. Path G, Opel A, Knoll A and Seufert J: Nuclear protein p8 is associated with glucose-induced pancreatic beta-cell growth. Diabetes 53 (suppl 1): 82-85, 2004.

9. Vasseur S, Folch-Puy E, Hlouschek V, Garcia S, Fiedler F, Lerch MM, Dagorn JC, Closa D and Iovanna JL: P8 improves pancreatic response to acute pancreatitis by enhancing the expression of the anti-inflammatory protein pancreatitisassociated protein I. J Biol Chem 279: 7199-7207, 2004.

10. Bratland A, Risberg K, Maelandsmo GM, Gutzkow KB, Olsen OE, Moghaddam A, Wang MY, Hansen CM, Blomhoff HK, Berg JP, Fodstad $\mathrm{O}$ and Ree AH: Expression of a novel factor, com1, is regulated by 1,25-dihydroxyvitamin D3 in breast cancer cells. Cancer Res 60: 5578-5583, 2000.

11. Malicet C, Lesavre N, Vasseur S and Iovanna JL: P8 inhibits the growth of human pancreatic cancer cells and its expression is induced through pathways involved in growth inhibition and repressed by factors promoting cell growth. Mol Cancer 2: 37, 2003.

12. Vasseur S, Hoffmeister A, Garcia S, Bagnis C, Dagorn JC and Iovanna JL: P8 is critical for tumour development induced by rasV12 mutated protein and E1A oncogene. EMBO Rep 3: 165-170, 2002.

13. Goruppi S and Kyriakis JM: The pro-hypertrophic basic helixloop-helix protein $\mathrm{p} 8$ is degraded by the ubiquitin/proteasome system in a protein kinase B/Akt- and glycogen synthase kinase3 -dependent manner, whereas endothelin induction of $\mathrm{p} 8$ mRNA and renal mesangial cell hypertrophy require NFAT4. J Biol Chem 279: 20950-20958, 2004.

14. Garcia-Montero AC, Vasseur S, Giono LE, Canepa E, Moreno S, Dagorn JC and Iovanna JL: Transforming growth factor beta-1 enhances Smad transcriptional activity through activation of $\mathrm{p} 8$ gene expression. Biochem J 357: 249-253, 2001.

15. Jiang WG, Watkins G, Douglas-Jones A, Mokbel K, Mansel RE and Fodstad O: Expression of Com-1/p8 in human breast cancer, and its relevance to clinical outcome and ER status. Int $\mathbf{J}$ Cancer 117: 730-737, 2005.

16. Jiang WG, Davies G and Fodstad O: Com-1/p8 in oestrogen regulated growth of breast cancer cells, the ER-beta connection. Biochem Biophys Res Commun 330: 253-262, 2005.

17. Jiang WG, Watkins G, Lane J, Douglas-Jones A, Cunnick GH, Mokbel M and Mansel RE: Prognostic value of Rho familty and and rho-GDIs in breast cancer. Clin Cancer Res 9: 6432-6440, 2003.

18. Jiang WG, Grimshaw D, Lane J, Martin TA, Parr C, Davies G, Laterra $\mathrm{J}$ and Mansel RE: Retroviral hammerhead transgenes to cMET and HGF/SF inhibited growth of breast tumour, induced by fibroblasts. Clin Cancer Res 9: 4274-4281, 2003.

19. Kang H, Mansel RE and Jiang WG: The role of Stroma-derived factor 1 (SDF-1) in the migration and invasion of breast cancer cells. Int J Oncol 26: 1429-1434, 2005.

20. Jiang WG, Davies G, Martin TA, Parcc C, Watkins G, Mason MD, Mokbel K and Mansel RE: Molecular targeting of matrilysin and its impact on tumour growth in vivo, the potential implications in breast cancer therapy. Clin Cancer Res 11: 6012-6019, 2005.

21. Carracedo A, Lorente M, Egia A, Blazquez C, Garcia S, Giroux V, Malicet C, Villuendas R, Gironella M, Gonzalez-Feria L, Piris MA, Iovanna JL, Guzman M and Velasco G. The stress-regulated protein $\mathrm{p} 8$ mediates cannabinoid-induced apoptosis of tumor cells. Cancer Cell 9: 301-312, 2006.

22. Malicet C, Giroux V, Vasseur S, Dagorn JC, Neira JL and Iovanna JL: Regulation of apoptosis by the p8/prothymosin (alpha) complex. Proc Natl Acad Sci USA 103: 2671-2676, 2006. 